\title{
Article
}

\section{Examining the portrayal of homophobic and non-homophobic aggression in print media through an integrated grounded behavioural linguistic inquiry (IGBLI) approach}

Birch, Philip, Ozanne, Rebecca Louise and Ireland, Jane Louise Available at http://clok.uclan.ac.uk/17139/

Birch, Philip, Ozanne, Rebecca Louise and Ireland, Jane Louise ORCID: 00000002-5117-5930 (2017) Examining the portrayal of homophobic and nonhomophobic aggression in print media through an integrated grounded behavioural linguistic inquiry (IGBLI) approach. Journal of Forensic Practice, 19 (3). pp. 239-244. ISSN 2050-8794

It is advisable to refer to the publisher's version if you intend to cite from the work. http://dx.doi.org/10.1108/JFP-02-2017-0003

For more information about UCLan's research in this area go to http://www.uclan.ac.uk/researchgroups/ and search for < name of research Group>.

For information about Research generally at UCLan please go to http://www.uclan.ac.uk/research/

All outputs in CLoK are protected by Intellectual Property Rights law, including Copyright law. Copyright, IPR and Moral Rights for the works on this site are retained by the individual authors and/or other copyright owners. Terms and conditions for use of this material are defined in the policies page. 
Examining the portrayal of Homophobic and Non Homophobic Aggression in print media through an Integrated Grounded Behavioural Linguistic Inquiry (IGBLI) approach

\begin{tabular}{|r|l|}
\hline Journal: & Journal of Forensic Practice \\
\hline Manuscript ID & JFP-02-2017-0003.R1 \\
\hline Manuscript Type: & Brief literature/discussion Paper \\
\hline Keywords: & $\begin{array}{l}\text { Homophobic aggression, Heterosexual aggression, Print media, Integrated } \\
\text { Grounded Behavioural Linguistic Inquiry (IGBLI) approach, Homophobia, } \\
\text { LGBTI discrimination }\end{array}$ \\
\hline
\end{tabular}




\section{Introduction.}

This brief report recognises that the media creates an understanding of the social world for individuals and wider society. As such this social institution can impact on homophobia in society through its portrayal of the LGBTI community. By utilising a new and innovative qualitative research method, an Integrated Grounded Behavioural Linguistic Inquiry (IGBLI) approach devised by the co-authors Ireland and Birch, newspaper articles from four daily newspapers in circulation within the USA, Canada, the UK and Australia are examined. This cross-cultural examination illustrates differences in the themes contained in reports of homophobic aggression when compared to reports of non homophobic aggression. This article first begins by considering the nature and extent of homophobia.

\section{Nature and extent of Homophobia: An overview.}

According to the Anti-Defamation League, homophobia can be understood as:

'...the hatred or fear of homosexuals - that is, lesbians and gay men - sometimes

leading to acts of violence and expressions of hostility. Homophobia is not confined to any one segment of society, and can be found in people from all walks of life.

Organized hate groups have viciously attacked homosexuals and have used especially violent language in attempting to persecute and intimidate them'.

(Accessed at: http://archive.adl.org/hate-patrol/homophobia.html\#.VdFkVUsqu0s on $17^{\text {th }}$ August, 2015).

The Australia Human Rights Commission (2014) reported on the everyday types of discrimination, harassment and hostility LGBTI people face, including verbal and physical forms of abuse, with approximately $50 \%$ of LGBTI community members admitting to hiding their sexuality due to fear of exposure to discrimination (Australia Human Rights Commission, 2014). As a consequence of this discrimination, harassment and hostility LGBTI people have experienced over time, and continue to experience, it is important to explore and understand the effects of homophobia.

\section{The portrayal of the LGBTI community in the media.}


According to Couldry (2009), the media contributes to and sustains unequal power within the social world. This has previously been illustrated through the work of Bourdieu (1991) who recognised that the media has the power to 'construct reality' (pp. 166), which can also be termed as symbolic power. The role of the media, in particular print media, in contributing to the outcome of policy issues, such as same sex marriage, is also well documented and evidenced through the theory of 'agenda setting' (Hester and Gibson, 2007).

Poole (2014) examined the way in which gay males have been represented in the media over a 10 -year period, finding that hetero-normative identities dominate the media. Poole's research recognises how the media is prone to stereotyping and communicating negative consequences for those who do not fit conventional norms and values. The implication of this work resonates with Bourdieu's (1991) observations considered above. The findings of Poole (2014) are illustrated through the earlier work of Padva (2007) who reviewed films depicting members of the LGBTI community. Padva noted that homosexuals were often portrayed in the media as 'confused youths' up until the late 1980s, and since then have been shown as individuals who did not conform to gender identities and who were often bullied. The conclusions drawn from this type of research is that the media, in a large part, is driven by heterosexuality and its dominance in society, which can engender homophobia in society. This implies the media can contribute to addressing the types and levels of discrimination experienced by the LGBTI community, including that of homophobia.

The language used by the media, and how it influences society has been examined in the work of Henley et. al. (2002), who conducted a content analysis of newspaper articles covering anti-gay attacks. While variation was found amongst these newspaper reports, the researchers noted that in one newspaper there were both fewer and less specific nominalisations, which are claimed to obscure agency when describing an anti-gay crime as opposed to anti-straight violence. It was concluded by Henley et. al. (2002) that language can influence how readers perceive the amount of harm done to a victim. Analysis of media content, especially with regards to print media, commonly drawn upon content analysis, the use of any type of behavioural assessment to examine media content, however, has been neglected within the 
empirical research, especially with regards to the portrayal of individuals and groups. Therefore any consideration of antecedents and reinforcing factors surrounding behaviours of interest from being understood, the core aims of a behavioural assessment (see Lee-Evans, 1994) do not feature within this type of research. The current article, therefore, contributes to redressing this neglect by developing a new and innovative research method in order to analyse the portrayal of homophobic aggression and non homophobic aggression in print media. By doing so, the following analysis incorporates a behavioural assessment framework.

\section{Methodology}

Sample

One homosexual aggressive incident newspaper report and one heterosexual aggressive newspaper report was selected from a daily newspaper in the USA, Canada, the UK and Australia, over a 5-year period, between November 2011 and August 2016. Of the four print newspapers selected from each of the named countries, the print newspaper was chosen due to the fact it was one of the most circulated papers in their respective countries.

A total of eight articles were therefore selected, based on a purposive strategy $(n=4$ articles containing homophobic aggression; $n=4$ articles containing non homophobic aggression).

Analytical approach

Three distinct, yet complimentary qualitative research methods were adopted in the analysis: 1) a grounded theory approach to analysis, 2) a behavioural assessment framework in the form of a SORC (see Lee-Evans, 1994) and 3) the Linguistic Inquiry and Word Count method (Tausczik \& Pennebaker, 2010). These three components are brought together in order to develop a new and innovating qualitative research method entitled an Integrated Grounded Behavioural Linguistic Inquiry (IGBLI) devised by the co-authors Ireland and Birch. This approach was adopted to allow for the content to be captured and explored without prejudice (through the use of a grounded theory approach), interpreted (through the use of a SORC framework) allowing for an exploration in how the report was being expressed through language 
(through the use of a linguistic inquiry and word count analysis). The findings are presented below.

\section{Findings}

Component 1 of the IGBLI: Grounded Theory analysis component

A grounded theory approach was the first step of the IGBLI. The process was conducted using the stages of the approach as noted by Schroth (2013), namely generating categories, by noting key points in the data and grouping similar content to produce concepts. By grouping concepts together broader categories emerged, which also contained sub themes. The categories and sub themes were scrutinised by a second researcher to ensure inter-rater reliability in which six broad categories of effects to victims, responses from others, motivation for the assault, perpetrator behaviour, characteristics of those involved and Criminal Justice issues arose from this analysis.

Overall, while the categories that emerged from the first stage analysis offers some similarities in terms of how the media portrays both homophobic and non homophobic aggression, the nature and extent of this portrayal is different between the two cohorts. This is reflected through various categories and sub themes, which emerged from this analysis such as effects to victims and motivation for the assault. For example, the focus of the news reports for homophobic aggression significantly focussed on the emotional impact of the incident and the severity of the injury, compared to non homophobic aggressive reports. Reports of non homophobic aggression appeared to focus more on facts such as the time of the attack and perpetrator characteristics. These results are clearly tentative but they do suggest some emerging themes worthy of further study. The next step of the Integrated Grounded Behavioural Linguistic Inquiry (IGBLI) approach aimed to examine this in more detail using a behavioural [functional] assessment. 
The SORC analysis, a behavioural assessment, as noted earlier in this chapter, accounts for the antecedents and reinforcing factors surrounding behaviours of interest (Lee-Evans, 1994). A SORC comprises four components: S setting/antecedent, $\mathrm{O}$ - organism variables, $\mathrm{R}$ - response and $\mathrm{C}$ - consequences, namely reinforcers (Lee-Evans, 1994: 20). It allows for further interpretation of the aggression reported on in the print media reports as opposed to a simple description of categories and themes that emerged through the grounded theory analysis. The SORC attempts to offer a function of the behaviour, in this instance aggression, through an interpretation of antecedents, background factors and potential reinforcers. SORC analyses were conducted across 8 articles in total, with an example of SORC presented below to illustrate this process. This article captures a homophobic aggressive incident.

Example SORC: Newspaper Report 1 - The United States, USA Today Report: Homophobic aggressive incident (The Associated Press, 2013); This reported on a fatal shooting in New York City. It was reported as an 'anti-gay hate crime'. The victim was walking with his companion. The perpetrator reportedly used homophobic slurs before shooting the victim in the cheek.

(S) Setting: The offence took place in a busy city, in the middle of a 'weekend midnight crowd' in a busy public place known as the 'bed rock of gay rights'. The perpetrator looked for confirmation that the two men were a couple before shooting, suggesting the possible importance of their homosexuality (i.e. specific trigger). Reports suggest the perpetrator may have felt slightly disinhibited at the time, supported by his actions prior to the crime when threatening individuals in a restaurant after urinating outside it. Homophobic slurs were used by the perpetrator and he confirmed the relationship between the victim and his partner before shooting.

(O) Organism variables: The perpetrator had been previously arrested for attempted murder, though little of this arrest was known. The use of homophobic slurs suggests 
a pre-existing negative belief system.

(R) Response: High intense violent response (i.e. shooting of the victim).

(C) Consequences: Potential positive reinforcement for the perpetrator through gaining notoriety by committing the crime in public and negative reinforcement through the remove of negative emotion/feelings of hate towards the victims.

Hypothesised function(s): To express homophobic views.

The SORC analysis of newspaper articles, illustrated by the example above, reflects differences in the way aggression towards homosexual and heterosexual people is portrayed in the media. Through the analysis of the aggression reported within print media amongst the four countries of the USA, Canada, the UK and Australia, the description with regards to the antecedents and what triggers an incident of homophobic aggression compared to a non homophobic aggression incident differ in terms of the amount of detailed offered. This difference is also found to be a feature in the SORC with regards to background factors and potential reinforcers, which are both more detailed features in the homosexual aggressive news reports than in the non homosexual incidents. While such findings preliminary and small scale, they do suggest the application of a behavioural assessment for analysing media content is worthy of further study.

Component 3 of the IGBLI: Linguistic Inquiry and Word Count (LIWC) analysis component

A Linguistic Inquiry and Word Count analysis (Tausczik \& Pennebaker, 2010) was used to examine the choice of words employed in these 8 articles consider in this IGBLI. The LIWC allowed for considering the news reports separately for the aggression towards homosexuals and the aggression towards non homosexuals. Pictures, adverts, unrelated words (such as date of publication and authors' name) were removed from the article prior to analysis, although titles of articles were 
retained. Text was checked from slang and abbreviations, as instructed (Pennebaker, Booth, Boyd, \& Francis, 2015). The results are presented in table 1 below in which the output from the LIWC text analysis is reported, this output also includes total word count as well as positive and negative words reflecting emotions.

$<<$ TABLE 1 HERE $>>$

To explore if these were significant, Mann-Whitney tests were conducted using SPSS. The only significant difference was for overall cognitive words $(U=.00, p=.021)$, which were higher for the homophobic aggression articles. This suggests that overall there was not a great difference in the way in which the reports of homophobic and non homophobic articles that were included in this study were communicated via written lanaguage. Although when reporting on homophobic aggression word selection indicates greater active thinking (i.e. cognitive words), suggesting these reports may be more reflective.

\section{Conclusion.}

In conclusion the variations in reporting styles and content presented in this study reflect the observations offered by existing research. For example, in research such as that by Poole (2014) it was noted that the media commonly treat certain individuals and groups such as the LGBTI community differently when compared to other individuals and groups. While scholars have argued that the way in which individuals are portrayed in the media has the potential to impact on the audience's acceptance of stereotypes, which ultimately may lead to discrimination such as homophobia. The media, therefore, has a duty to report and represent individuals and groups, such as those in the LGBTI community, in a fair and accurate way, and without prejudice. By engaging in such practice the media can contribute to a reduction and prevention in homophobia and help improve the health and wellbeing of the LGBTI community.

\section{References.}

ABC News (2016, March 9) Same-sex marriage: Let's get it sorted and move on. $A B C$ News. Accessed at: http://www.abc.net.au/news/2016-03-09/barnes-let's-get-it-sortedand-move-on/7231770 on 29th September, 2016. 
Anti-Defamation League (n.d.). Defining Homophobia. Accessed at: http://archive.adl.org/hate-patrol/homophobia.html\#.VdFkVUsqu0s on $17^{\text {th }}$ August, 2015.

Australian Human Rights Commission (2014). 'Face the facts: Lesbian, Gay, Bisexual, Trans and Intersex People. Sydney: Human Rights Commission.

Bourdieu, P. (1991). Language and symbolic power. Cambridge, MA: Harvard University Press.

Couldry, N. (2009). Does 'the media'have a future? European journal of communication, 24(4), 437-449.

Henley, N. M., Miller, M. D., Beazley, J. A., Nguyen, D. N., Kaminsky, D., \& Sanders, R. (2002). Frequency and specificity of referents to violence in news reports of anti-gay attacks. Discourse \& Society, 13(1), 75-104.

Hester, J. B., \& Gibson, R. (2007). The agenda-setting function of national versus local media: A time-series analysis for the issue of same-sex marriage. Mass Communication \& Society, 10(3), 299-317.

Lee-Evans, J.M. (1994). Background to behaviour analysis. In M. McMurran and J. Hodge (eds), The Assessment of Criminal behaviours of Clients in a Secure Setting. London: Jessica Kingsley.

Padva, G. (2007). Media and popular culture representations of LGBT bullying. Journal Of Gay \& Lesbian Social Services: Issues In Practice, Policy \& Research, 19(3-4), 105-118.

Pennebaker, J. W., Booth, R. J., Boyd, R. L., and Francis, M.E. (2015). 'Linguistic Inquiry and Word Count: LIWC2015'. Austin: Pennebaker Conglomerates.

Poole, J. (2014). Queer Representations of Gay Males and Masculinities in the Media. Sexuality \& Culture, 18(2), 279-290.

Schroth, S. T. (2013). ‘Grounded theory’. New York: Salem Press Encyclopaedia.

Tausczik, Y. R., and Pennebaker, J. W. (2010). The psychological meaning of words: LIWC and computerized text analysis methods. Journal of Language And Social Psychology, 29(1), 24-54.

The Associated Press. (2013, May 19). Police: Fatal NYC shooting an anti-gay hate crime. USA Today. Accessed at: http://www.usatoday.com/story/news/nation/2013/05/18/nyc-shooting-gay-hatecrime/2323175/ on 26th June, 2016. 


\begin{tabular}{|c|c|c|c|c|c|c|c|c|c|c|}
\hline & \multicolumn{5}{|c|}{ Articles referring to homophobic } & \multicolumn{5}{|c|}{$\begin{array}{l}\text { Articles referring to non homophobic } \\
\text { aggression }\end{array}$} \\
\hline & USA & Canada & UK & Australia & Total & USA & Canada & UK & Australia & Total \\
\hline $\begin{array}{l}\text { Self- } \\
\text { references (I, } \\
\text { me, my) }\end{array}$ & 0.34 & 2.25 & 1.35 & 1.26 & 1.13 & 1.63 & 0.00 & 0.36 & 0.00 & 0.94 \\
\hline Social words & 10.74 & 12.13 & 9.03 & 12.63 & 10.78 & 11.44 & 8.76 & 10.43 & 8.66 & 10.53 \\
\hline $\begin{array}{l}\text { Positive } \\
\text { emotions }\end{array}$ & 0.34 & 1.35 & 0.40 & 0.25 & 0.53 & 1.34 & 0.52 & 0.36 & 0.00 & 0.86 \\
\hline $\begin{array}{l}\text { Negative } \\
\text { emotions }\end{array}$ & 2.94 & 2.25 & 3.77 & 2.27 & 2.96 & 1.49 & 4.12 & 6.12 & 3.15 & 3.07 \\
\hline Overall & & & & & & & & & & \\
\hline $\begin{array}{l}\text { cognitive } \\
\text { words }\end{array}$ & 4.52 & 5.17 & 3.64 & 3.79 & 4.26 & 2.53 & 3.61 & 3.24 & 1.57 & 2.75 \\
\hline $\begin{array}{l}\text { Articles (a, } \\
\text { an, the) }\end{array}$ & 11.09 & 6.07 & 9.97 & 8.33 & 9.40 & 11.44 & 7.73 & 10.07 & 14.17 & 10.85 \\
\hline $\begin{array}{l}\text { Big words }(> \\
6 \text { letters) }\end{array}$ & 19.57 & 16.18 & 18.60 & 19.95 & 18.73 & 19.91 & 25.77 & 20.86 & 19.69 & 20.99 \\
\hline $\begin{array}{l}\text { Total word } \\
\text { count }\end{array}$ & 884 & 445 & 742 & 396 & 2467 & 673 & 194 & 278 & 127 & 1272 \\
\hline
\end{tabular}

Table 1: Linguistic Inquiry and Word Count text analysis of homophobic agression and non homophobic aggression in print media reports. 